\title{
A Guerra Híbrida e o Papel da Rússia no Conflito Sírio
}

\section{Hybrid War and the Role of Russia in the Syrian Conflict}

Rev. Bra. Est. Def. v. 3, nº 1, jan./jun. 2016, p. 189-203

ISSN 2358-3932

\section{LARLECIANNE PICCOLLI LAUREN MACHADO VALESKA FERRAZZA MONTEIRO}

\section{INTRODUÇÃO}

O presente artigo objetiva demonstrar como a atuação militar da Rússia na Síria pode ser caracterizada enquanto guerra híbrida, e como o papel russo no conflito evidencia a capacidade deste país em atuar como polo de poder no Sistema Internacional. Para tanto, são estabelecidos os seguintes objetivos específicos: (i) traçar um breve histórico sobre as relações Rússia-Síria; (ii) relatar o curso do conflito atual; (iii) apresentar o papel e os interesses da Rússia e dos Estados Unidos da América (EUA) no âmbito do conflito na Síria; (iv) indicar a relação entre a desestabilização da Síria e a crise de refugiados na Europa; e (v) inferir a possibilidade da intervenção militar russa auferir relação com a estabilização do fluxo migratório e, então, o consequente cessar das sanções econômicas ao país.

O desenvolvimento da pesquisa está condicionado ao uso de fontes bibliográficas diversas, as quais são primordialmente constituídas de artigos, dada a atualidade do assunto, e também livros que versem tangencialmente sobre o tema. Do mesmo modo, são utilizadas fontes primárias e notícias pertinentes. A hipótese principal a ser defendida indica que a estratégia russa na Síria é de guerra híbrida. As hipóteses secundárias demonstram

\footnotetext{
Larlecianne Piccolli - Doutoranda e Mestre em Estudos Estratégicos Internacionais pela Universidade Federal do Rio Grande do Sul. Bacharel em Relações Internacionais pela Faculdade América Latina. Contato: larle@hotmail.com.

Lauren Machado - Mestranda em Estudos Estratégicos Internacionais pela Universidade Federal do Rio Grande do Sul. Bacharel em Relações Internacionais pela Faculdade América Latina. Contato: lauren.machado@hotmail.com.

Valeska Ferrazza Monteiro - Graduanda em Relações Internacionais pela Universidade Federal do Rio Grande do Sul. Contato: valeska.ferrazza@gmail.com.
} 
(i) a atuação russa na Síria como um dos elementos que compõem a tentativa de Moscou em se estabelecer no Sistema Internacional enquanto polo de poder e (ii) as intenções russas na Síria enquanto plausíveis para frear o fluxo de refugiados à Europa e, indiretamente, como objeto de barganha frente aos países europeus para a resolução do conflito ucraniano.

\section{RELAÇÕES RÚSSIA-SÍRIA E O CONFLITO}

A história da Síria é marcada por instabilidade política e ingerência externa. Desde meados dos anos 1500 o território demarcado como sírio esteve sob o domínio do Império Turco-Otomano. Ao final da Primeira Guerra Mundial, após cerca de 400 anos da dominação turco-otomana, os sírios experimentaram um breve período de independência, proclamando Faisal Hussein Bin Hussein como rei. Contudo, logo em 1920, com a Conferência de San Remo, a qual dividiu os territórios anteriormente administrados pelo Império Turco-Otomano entre os vencedores da Primeira Guerra, conforme previamente definido pelo acordo Sykes-Picot, ${ }^{4}$ a Síria passa a ser colonizada pelo Estado Francês (Hall 2013). Apenas em 17 de abril de 1946, com o fim da Segunda Guerra Mundial, o Estado Sírio obteve sua independência da França.

No que concerne à relação entre soviéticos e sírios, essa foi iniciada com a assinatura de um acordo secreto, em 1946, pouco antes da declaração da independência síria. Alguns anos depois, em 1950, as relações avançaram no sentido de um pacto de não agressão, e da expansão da assistência econômica e militar soviética aos sírios. É preciso notar que, no contexto da Guerra Fria, a Síria se estabelecia como um país-satélite soviético no Oriente Médio, e era vista como aliada para garantir uma zona de influência na região, bem como a manutenção do equilíbrio nuclear ${ }^{5}$ (Aghayev, Katman 2012).

No ano de 1967, Israel é declarado o vencedor da Guerra dos Seis Dias e toma as Colinas de Golã da Síria, incitando um crescimento substancial do apoio e da presença militar soviética em território sírio. Ao final da década de 1970, através de um golpe que institui Hafez al-Asad no poder, dá-se início ao governo da família al-Assad na Síria, administração a qual corresponde ao ápice do relacionamento entre os países (Hall 2013).

Em 1971, objetivando assegurar suas linhas marítimas de comunicação (Sea Lines of Communication - SLOC) e o acesso aos mares quentes, a Rússia estabelece uma base naval em Tartus, permitindo sua presença no Mar Mediterrâneo (Figes 2010). Em seguida, em 1973, juntamente com o Egito, os sírios entram em guerra com Israel para reconquistar as Colinas de Golã, mas não conseguem atingir seu objetivo. Com a Guerra Civil Libanesa e a intervenção síria no conflito em 1976, há um afastamento nas relações sírio-soviéticas, período no qual a URSS reduziu seu apoio 
econômico e sua presença militar no Estado Sírio: Damasco, por sua vez, buscou assistência da Arábia Saudita. Não obstante esse curto período de tensão, em 1978 há uma reaproximação entre a União Soviética e a Síria (Hall 2013).

Ao longo dos anos 1980, as relações sírio-soviéticas avançaram consideravelmente, e, nesse período, a URSS apoiou fortemente a Síria nos aspectos econômico e militar. Em outubro de 1980 é concluído o Tratado de Amizade e Cooperação Sírio-Soviético, que, dentre diversos artigos, previa cooperação militar entre as partes, marcando a importância dessa relação (Aghayev, Katman 2012).

Com a morte de Hafez, seu filho Bashar al-Assad assume o governo sírio em 2000, sendo reeleito em 2007 por um referendo popular. Na esteira da Primavera Árabe, ${ }^{6}$ em 2011 eclode uma guerra civil no país. Diante da escalada do conflito, o Conselho de Segurança das Nações Unidas (CSNU) propôs estabelecer resoluções para a situação na Síria, porém, a Rússia vetou tais tentativas (Un 2014). De acordo com Machado e Mendelski (2015:15), o bloqueio russo às resoluções do Conselho de Segurança sobre a “[...] Síria é claramente político: a Rússia não está disposta a enfrentar a mesma situação de troca de regime ocorrida na Líbia”.

Mais tarde, em 2013, com o uso de armas químicas no conflito, os EUA ameaçaram um ataque unilateral para a solução da crise síria. Moscou, por sua vez, buscou impedir tais ações de Washington e agiu pela via diplomática e também militar. Ao mesmo tempo em que acordou com o presidente Bashar al-Assad sobre a entrega de seu arsenal de armas químicas à ONU, Moscou enviou para o Mediterrâneo navios do Mar Negro, do Norte e do Pacífico, alertando que não permitiria um ataque à Damasco (Anishchuk 2013; Oliveira, Brites, Reis 2013; Machado, Mendeslki 2015).

Ao longo de quatro anos de hostilidades na Síria, o conflito já transbordou as fronteiras do país e envolve atores internos, regionais e internacionais. Além dos mais de 470 mil mortos desde o início do conflito, há cerca de 7,6 milhões de deslocados, e mais de 4,1 milhões de refugiados. ${ }^{7}$ É preciso, portanto, indicar que há uma relação entre a desestabilização da Síria e a crise de refugiados na Europa, embora os destinos principais da população síria tenham sido os países vizinhos, como Turquia e Líbano (Unher 2015; Syria death 2016).

No que tange aos atores envolvidos, sob o aspecto interno, além das forças do governo, é possível destacar a ação dos rebeldes sunitas. Por outro lado, pelo aspecto regional, ressalta-se o papel de Irã, Turquia e Arábia Saudita, ademais do envolvimento do Hezbollah e dos curdos na crise. Concomitantemente, é necessário mencionar a ascensão do Estado Islâmico (EI), ${ }^{8}$ que atua tanto na Síria quanto no Iraque, e detém o controle 
de porções de ambos territórios (Rodgers et al. 2015). No que concerne aos atores internacionais, Rússia e EUA podem ser citados como partes da guerra na Síria (Ghotme, Ripoll 2014). Desde setembro de 2014, uma coalizão liderada por Washington está realizando ataques aéreos tanto em território sírio quanto iraquiano, com o objetivo declarado de enfraquecer o EI (Rodgers et al. 2015). Um ano depois, ao final de setembro de 2015, a Rússia iniciou bombardeios na Síria.

Há uma ofensiva conjunta, em Aleppo, realizada pelas tropas de Bashar al-Assad, do Irã e do Hezbollah, que conta com cobertura aérea russa, evidenciando que a prioridade russa é apoiar a administração síria, no sentido de inibir uma troca de governo por ingerência externa. Além disso, grande parte dos bombardeios russos tem sido em cidades disputadas entre Assad e os grupos rebeldes (Homs, Hama e Idlib, por exemplo). Recentemente, Putin afirmou que seu objetivo com a ação na Síria se concentra na estabilização das autoridades legítimas e no estabelecimento de condições para atingir um acordo político (Lima 2015).

\section{A GUERRA HÍBRIDA E A ATUAÇÃO DA RÚSSIA NA SÍRIA}

Para caracterizar a ação russa recente no conflito sírio - desde setembro de 2015 - utiliza-se, aqui, o conceito de guerra híbrida. Este conceito foi empregado, inicialmente, por autores como Hoffman (2007), para descrever as novas ameaças que surgiram aos Estados Unidos no século XXI, as quais, segundo o autor, seriam compostas por diferentes tipos de guerra - convencional, irregular, terrorista - conduzidas por um único ator inimigo - estatal ou não. O estudo de caso deste autor é sobre a guerra de Israel contra o Hezbollah em 2006, tendo o último se utilizado da guerra híbrida. Para a situação da Rússia na Síria, no entanto, far-se-á uma atualização deste conceito a partir de estudos mais recentes do tema.

Kofman e Rojansky (2015) incluem na sua conceituação de guerra híbrida, além dos aspectos levantados por Hoffman (2007), o elemento da guerra de informação. Os autores analisam mais especificamente o caso russo à luz deste conceito, argumentando que Moscou se utiliza de abordagem externa que combina diferentes tipos de projeção de poder. Snegovaya (2015) também ressalta o aspecto da guerra informacional na atuação externa russa recente, analisando a atuação desta na Ucrânia em 2014. Por fim, Cordesman (2015) avalia que a atuação militar russa na Síria, de fato, é combinada com guerra política e informacional, sendo o objetivo final de Moscou pressionar o Ocidente para realizar a transição política na Síria, garantindo assim a manutenção da influência russa em posto avançado no Oriente Médio. 
A partir deste conceito ampliado de guerra híbrida - guerra de informação ou propaganda, diplomacia e guerra política, guerra convencional, guerra irregular, guerra proxy - se discutirá a atuação russa no conflito sírio. Primeiramente, o aspecto que chama atenção no conflito é a guerra de propaganda ou de informação russa. Moscou tem passado a ideia de transparência a respeito da sua atuação militar na Síria: houve cobertura diária dos ataques aéreos - por meio de vídeos, fotos, entrevistas - que circularam em diversos meios de divulgação internacional. Os russos, assim, pretendem convencer de sua capacidade de fazer ataques cirúrgicos e efetivos, que, de fato, destroem as instalações do Estado Islâmico e ajudam o governo sírio a reconquistar territórios - uma vez que os bombardeios devem atuar em conjunto com as tropas em solo.

Em segundo lugar, a guerra convencional está, claramente, presente. A Rússia tem usado, principalmente, forças militares regulares para intervir na Síria, como é o caso da aviação, baseada no aeroporto Bassel al-Assad, em Latakia - composta de caças de ataque ao solo, caças bombardeiros, helicópteros de ataque - e da Marinha, tanto do Mar Cáspio quanto do Mediterrâneo Leste - composta por corvetas e submarinos que fizeram ataques ao território sírio. Em terceiro lugar, a diplomacia tem atuado em conjunto com estes aspectos. O presidente sírio Bashar al-Assad, por exemplo, viajou à Moscou no mês seguinte à intervenção russa, o que demonstra articulação política e diplomática entre os países. Além disso, a Rússia esteve presente nas discussões em Viena, em outubro de 2015, acerca do conflito sírio, o que evidencia tanto sua relevância na resolução da crise quanto sua capacidade de vincular a diplomacia e a política externa aos objetivos militares.

Por fim, a presença tanto da guerra irregular quanto da guerra proxy não deve ser descartada. Anteriormente à intervenção russa, aliás, alguns autores caracterizavam o conflito sírio como proxy, como é o caso de Oliveira, Brites e Reis (2013) que destacavam a inserção de vários atores regionais no teatro sírio por meio de proxies, como Arábia Saudita, Turquia e Irã. Apesar da intervenção russa, esta realidade permanece. Além disso, estes grupos se utilizam tanto da guerra irregular quanto da guerra convencional, complexificando a crise e reforçando seu caráter híbrido.

\section{ATUAÇÃO RUSSA PERANTE O CONFLITO SÍRIO: ASSERTIVIDADE E RETOMADA DA RELEVÂNCIA}

No que concerne aos interesses da Rússia no conflito sírio, evidencia-se que o posicionamento russo no sistema internacional vem ganhando caráter mais assertivo desde que Vladimir Putin assumiu a presidência do 
país nos anos 2000. A partir de então, a Rússia tem buscado um (re) posicionamento no sistema internacional, via pela qual tem dado voz a seus objetivos e interesses perante a arena política internacional.

Há de sublinhar que a visão-guia desta política externa é pautada por uma percepção multipolar e multivetorial do sistema internacional, estrutura a qual se coloca como mais propícia aos interesses nacionais russos. Neste sentido, o intento é pela manutenção da soberania estatal e integridade territorial russa, estabelecimento de condições estáveis para o crescimento e desenvolvimento econômico do país, dentre outros. Em um escopo global, agir de forma a promover a paz e a estabilidade e segurança internacional vem pari passu à consolidação de um sistema internacional justo e democrático, baseado em um processo decisório coletivo; no qual a cooperação internacional se dê em termos vantajosos e equânime aos envolvidos, bem como o respeito aos princípios do direito internacional (Okuneva 2010; Russia 2013).

$\mathrm{O}$ ímpeto de Moscou em salvaguardar seus interesses na arena internacional é perceptível ao passo de seu envolvimento em frentes nas quais evidenciam-se possíveis ameaças a estes. Em breve retrospectiva elenca-se a Guerra de Kosovo, o conflito russo-georgiano, a recente crise ucraniana e o posicionamento na Síria enquanto factuais das predileções russas no sistema internacional. Ainda, importa ressaltar, que a expansão da Organização do Tratado do Atlântico Norte (Otan), somada ao estabelecimento do sistema de defesa antimísseis europeu (Europen Phased Adaptative Aproach-EPAA), tem desencadeado ações defensiva-reativas ${ }^{9}$ de Moscou (Piccolli 2012).

Destarte, é plausível a compreensão da posição de Moscou em relação à Damasco como um reflexo à securitização da agenda internacional pautada pelo governo norte-americano. As incursões estadunidenses (e aqui correlaciona-se também seus aliados) no Oriente Médio (Iraque-2003, Líbia-2011) vão de encontro à propositiva russa de valoração de fóruns multilaterais de negociação, bem como ultrajam o papel concedido à Organização das Nações Unidas (ONU) no tocante à manutenção da paz e segurança mundial. Além disso, o constante avanço das forças militares norte-americanas no entorno russo é interpretado por Moscou como uma afronta aos interesses nacionais do país, pautados pela segurança e integridade territorial, e pela defesa de seus interesses e áreas de influência.

As análises então tangenciam que o posicionamento russo no conflito sírio perpassa o suporte histórico ao governo Assad, sendo possível inferir aspectos pertinentes aos interesses russos no sistema internacional descritos nas diretrizes de sua política externa. Tais aspectos, complementares e não excludentes, transcorrem de pretensões econômicas, políticas e estratégicas de Moscou na região. 
Em termos econômicos, cabe um adendo ao interesse econômico dos EUA no conflito (também representado pela União Europeia e Turquia). O contraponto de interesses russos e ocidentais se dá entre projetos concorrentes para o abastecimento ao mercado europeu. Por um lado, o projeto sírio-iraquiano-iraniano (apoiado pelos russos) de construção do Gasoduto Islâmico para exportação de gás iraniano e russo para a Europa. Por outro, o projeto de construção de um gasoduto que abasteceria a Europa a partir das reservas do Catar, através dos territórios da Turquia, Arábia Saudita, Jordânia, Síria e Israel (Robbinson 2013). Destarte, é plausível pontuar que o conflito de interesse econômico está presente nas ações de Washington e Moscou no Oriente Médio, seja por suas atuações diretas e/ou indiretas através de seus proxies regionais. Outrossim, Moscou vislumbra a manutenção de mercados consumidores de hidrocarbonetos russos, mas também a participação em projetos que garantam a transferência de know-how e investimentos.

Faz-se referência, então, ao viés estratégico que a Rússia dá a sua participação no conflito, tal qual é reflexo da necessidade de manutenção de seu posto avançado no Oriente Médio. Em primeira instância, o posicionamento é auferido pela presença em Tartus, assegurando as linhas marítimas de comunicação (SLOCs) e, consequentemente, o acesso aos mares quentes, bem como facultando a presença russa no Mar Mediterrâneo. Importa igualmente as posições angariadas através base aérea de Hmeymim em Latakia, no noroeste da costa mediterrânea do país, servindo para reiterar o posicionamento avançado na região.

Ainda, Moscou utiliza suas ações na Síria como uma via de demonstração das capacidades de suas forças aeroespaciais e navais, posicionando-se de forma altiva frente aos demais pares internacionais envolvidos em arranjos de coalizão para estabilização do conflito. Neste sentido, merece destacar que a base aérea de Hmeymim foi organizada de modo a oferecer infraestrutura completa para contingentes militares russos, se transformando no principal centro estratégico para as ações russas na Síria. Ademais de atender as necessidades de acomodação dos militares, possui capacidade de acolher aeronaves de transporte (o cargueiro super-jumbo Antonov An-124 Ruslan e o Tupolev Tu-76), e aeronaves e helicópteros militares de combate e de suporte (Sukhoi Su-24M, Sukhoi Su-25, Sukhoi Su-34, Mi-24 e Mi-8) (Russian Airbase 2015). Sublinha-se ainda a instalação do sistema de defesa antimísseis $\mathrm{S}-400$, permitindo proteção ao espaço aéreo sírio de abrangência do sul da Turquia até o norte de Israel (Russia confirms S-400 2015; Xenakis 2015). Não menos importante é a ação da marinha russa a partir de sua frota no Mar Cáspio, a qual lançou mísseis via sistema Kalibr $3 \mathrm{M}-54 \mathrm{Klub}$ (alcance de até $2.500 \mathrm{~km}$ ) que atingiram alvos 
do Estado Islâmico na Síria (Four Russian warship 2015; Lions 2015). Tais proposições demonstram a capacidade de Moscou em conduzir com destreza operações militares longe de suas fronteiras, bem como demonstram forte e crescente poderio militar.

A estabilização do avanço e das ações do Estado Islâmico, importa ao interesse de combate ao terrorismo mundial, mas vislumbra possíveis prejuízos frente a uma desestabilização da parte sul de seu território. ${ }^{10} \mathrm{Nesta}$ lógica, uma possível expansão das ações do EI para a região do Cáucaso, bem como a propagação e o vínculo de células terroristas com os separatistas do sul, atentam ao Kremlin posicionamento assertivo, deveras a barrar, senão quanto neutralizar, o avanço de posições extremistas na região como meio de manutenção de seu pacto federativo e, em última instância, sua integridade territorial.

Em termos políticos, evidencia-se a proposição, anti-intuitiva, de que os avanços frente ao EI e a consolidação das forças do governo sírio impactarão na redução do fluxo de imigrantes para o território europeu, podendo este ser utilizado como mecanismo de barganha para a negociação da flexibilização das sanções impostas à Moscou por conta do conflito ucraniano. Valentyn Badrak aponta como perturbador o fato de ações russas na Síria, as quais aludem para uma estabilização do conflito, serem recebidas positivamente por potências ocidentais (em especial Alemanha e França) em comuta à um posicionamento mais duro em relação a Ucrânia - forçando eleições na região de Donbass, por exemplo (Honcharov 2016). Apesar das declarações de Peter Poroschenko apontarem confiança nos parceiros ocidentais para a resolução e aplicação dos acordos de Minsk e, então, não utilização da Ucrânia enquanto moeda de barganha, recentes declarações dos governos alemão e francês geram dubiedade sobre o rumo das negociações (President: Ukraine will 2015).

Assim sendo, por um lado, a Alemanha, a partir das declarações de seu vice-chanceler Sigmar Gabriel, dá ênfase ao fato que o conflito na Síria não pode ser resolvido sem a ajuda da Rússia e que, então, não é plausível, pari passu, solicitar auxílio e isolá-la com sanções econômicas (El vicecanciller de 2015; Germany considers relaxing 2016). Por outro, a câmara baixa do Parlamento francês votou a favor de documento de caráter recomendatório ao Executivo para que cancele as medidas econômicas restritivas de comércio com a Rússia (Bogdanov, Neroznikova, Vzglyad 2016). Ainda, países como Itália e Hungria tencionam-se contrariamente a uma extensão de sanções à Rússia (Germany considers relaxing 2016). Imputa-se então que, ademais dos esforços das potencias ocidentais para fazer valer-se as proposições dos acordos de Minsk para resolução do conflito ucraniano, e vincularem estas ao abrandamento das sanções econômicas à Rússia, as 
ações assertivas da Rússia para com a estabilização do conflito sírio impelem significativo peso nas negociações em torno da Ucrânia.

A conduta de Moscou no conflito sírio reflete os ímpetos da retomada da assertividade e pragmatismo da política externa russa a partir dos anos 2000. A timidez inicial, reflexo das debilidades econômicas e políticas da década de 1990, dá espaço para uma atuação objetiva e funcional a favor da defesa de seus interesses a nível nacional, regional e global. Ao fim e ao cabo, o posicionamento da Rússia frente ao conflito sírio reflete a tentativa (válida e pujante) de Moscou em se (re)estabelecer no sistema internacional como polo de poder.

\section{CONSIDERAÇÕES FINAIS}

O estudo realizado procurou elucidar uma abordagem exploratória do papel cumprido pela Rússia no conflito sírio. Trata-se, portanto, de uma análise cuja abordagem temporal contemporânea pode sofrer inflexões e mudanças no curso da pesquisa, e cujas hipóteses podem ser falseáveis e cabíveis de revisão, haja visto a atualidade do tema. A partir da pesquisa corrobora-se então que sim, a ação russa na Síria traz componentes que a caracterizam como guerra híbrida, tais como a conjunção de operações militares convencionais e guerra informacional, ante um inimigo de caráter subestatal. Ainda, valer-se de transparência em relação às incursões realizadas e não relutar em atingir uma solução político-diplomática para a contenda, mostra a interface dos diversos aspectos que constituem a prerrogativa de um conflito híbrido.

A perspectiva subjacente é de uma retomada do posicionamento da Rússia enquanto polo de poder relevante no sistema internacional. É preciso esclarecer, aqui, que não apenas o conflito sírio - ou mesmo a guerra híbrida - colocariam, por si próprios, a Rússia enquanto potência internacional: de fato, existem outros elementos - aqui não detalhados - que explicariam esta realidade. Há que se considerar, no entanto, que a atuação praticamente autônoma do país em uma das crises hodiernas mais importantes e complexas - conseguindo realizar intervenção militar de apoio direto ao governo de Assad, enquanto ao mesmo tempo há uma operação ocidental (Operation Inherent Resolve) em curso - mostra como Moscou cada vez mais se posiciona como ator relevante no SI. Isso se consolida na participação russa nas negociações de Viena, em outubro de 2015, ao lado das principais potências regionais (Turquia, Arábia Saudita) e extrarregionais (Estados Unidos, Inglaterra, Alemanha, França).

São cognoscíveis, portanto, os interesses político-militares, estratégicos e econômicos que envolvem o influxo russo na região. Em termos políti- 
co-militares, traduzem-se em assinalar à comunidade internacional a capacidade do Kremlin em atuar como polo de poder no Sistema Internacional, seja no âmbito da negociação, seja na projeção de capacidades militares, ou ainda no imperativo do uso da força no entorno regional. O viés estratégico, por sua vez, aponta a necessidade de assegurar as linhas marítimas de comunicação com o Mediterrâneo, assim como o posto avançado em Tartus. No tocante às questões econômicas, é perceptível a relevância dada por Moscou em manter-se presente e participativa no estabelecimento de projetos que vinculem a dependência europeia de hidrocarbonetos seus e de aliados. O pragmatismo da política externa russa vai além: compreende sua intervenção militar na Síria como via plausível à estabilização do fluxo migratório para Europa, se utilizando deste como instrumento de barganha perante os países europeus, a fim de cessar as sanções econômicas impostas por conta da crise na Ucrânia.

Como dito, a atualidade do conflito infere em constantes mudanças e alterações nos rumos deste. No entanto, pondera-se que a participação russa no conflito está bem delimitada a partir dos interesses e objetivos de Moscou no cenário global, evidenciando sua projeção como polo de poder internacional.

\section{REFERÊNCIAS}

Aghayev, E., Katman, F. 2012. Historical Background and the Present State of the Russian-Syrian Relations. European Researcher, 35 (11.13): 2066-2070.

Anishchuk, A. 2013. Russia, U.S. deny date set for Syria peace conference. Reuters, Moscow, 17 oct. Disponível em: http://www.reuters.com/article/2013/10/17/ us-syria-crisis-conference-idUSBRE99GoKG20131017. Acesso em: 12 nov. 2013.

Bogdanov, Y., Neroznikova, Y., Vzglyad. 2016. French parliament votes in favor of lifting EU sanctions against Russia. Russia Beyond the Headlines. Moscow, 29 Apr. Disponível em http://rbth.com/international/2016/04/29/french-parliament-votes-in-favor-of-lifting-eu-sanctions-against-russia_589227. Acesso em: 10 jun. 2016.

Cordesman, A. H. 2015. Russia in Syria: Hybrid Political Warfare. Center for Strategic and International Studies. Disponível em: https://www.csis.org/analysis/ russia-syria-hybrid-political-warfare. Acesso em: 12 out. 2015.

El vicecanciller de... 2015. El vicecanciller de Alemania pide poner fin a "la constante flagelación ideológica” contra Rusia. Russia Today. Moscú, 12 out. Disponível em: https://actualidad.rt.com/actualidad/188339-vicecanciller-alemania-oponer-flagelacion-rusia. Acesso em: 11 jun. 2016. 
Figes, O. 2010. The Crimean War: A History. New York: Metropolitan Books.

Four Russian warship... 2015. 4 Russian warships launch 26 missiles against ISIS from Caspian Sea. Russia Today, 07 Oct. Disponível em: https://www.rt.com/ news/317864-russian-warships-missiles-launch/. Acesso em: 12 jun. 2016.

Germany considers relaxing... 2016. Germany considers relaxing sanctions against Russia. Deutsch Welle, 27 May. Disponível em: http://www.dw.com/en/germany-considers-relaxing-sanctions-against-russia/a-19286513. Acesso em: 11 jun. 2016.

Ghotme, R., Ripoll, A. 2014. Las Relaciones Internacionales de la Guerra Civil Siria: Estados Unidos y Rusia en la Lucha por el Poder Internacional. Revista de Relaciones Internacionales, Estrategia y Seguridad, 9 (2): 49-76.

Hall, C. 2013. The history of Syria: 1900-2012. Boston: Charles River Editors.

Hoffman, F. 2007. Conflict in the 21st Century: The Rise of Hybrid Wars. Arlington: Potomac Institute for Policy Institute.

Honcharov, K. 2016. Why Kremlin takes step back on Syria. Unian Information Agency. 18 Mar. Disponível em: http://www.unian.info/politics/1293532-why-kremlin-takes-step-back-on-syria.html. Acesso em: 11 jun. 2016.

Kofman, M., Rojansky, M. 2015. A Closer Look at Russia's Hybrid War. Washington: Woodrow Wilson International Center for Scholars.

Lima, J. A. 2015. O que motiva a ação militar da Rússia na Síria? Carta Capital, 20 set. Disponível em: http://www.cartacapital.com.br/internacional/o-que-motiva -a-acao-militar-da-russia-na-siria-2373.html. Acesso em: 11 out. 2015.

Lions, P. 2015. Russia's Kalibr Cruise Missiles, a New Weapon in Syria Conflict. The New York Times. New York, 08 Oct. Disponível em: http://www.nytimes. $\mathrm{com} / 2015 / 10 / 09 /$ world/middleeast/russias-kalibr-cruise-missiles-a-new-weapon-in-syria-conflict.html?_r=0. Acesso em: 11/06/2016.

Machado, L., Mendelski, B. 2015. A Política Externa e a Atuação Russa no Conselho de Segurança das Nações Unidas de 1991-2014. Revista Geopolítica, 6 (1): 46-64.

Okuneva, L. 2010. Os 25 Anos da Política Externa da URSS/Rússia: questões-chave, evolução, perspectivas (1985-2010). In: Pecequillo, C. S. (Org.). A Rússia: desafios presentes e futuros. Curitiba: Juruá, 23-57.

Oliveira, L. K., Brites, P. V. P., Reis, J. A. da S. 2013. A guerra proxy na Síria e as disputas estratégicas russo-estadunidenses no Oriente Médio. Mundorama, 20 set. 
Disponível em: http://mundorama.net/2013/09/20/a-guerra-proxy-na-siria-eas-disputas-estrategicas-russo-estadunidenses-no-oriente-medio-por-lucas-kerrde-oliveira-pedro-vinicius-pereira-brites-e-joao-arthur-da-silva-reis/. Acesso em: 30 nov. 2015.

Piccolli, L. 2012. Europa enquanto condicionamento da política externa e de segurança da Rússia: o papel da defesa antimíssil. Dissertação (Mestrado). Universidade Federal do Rio Grande do Sul.

President: Ukraine will... 2015. President: Ukraine will make decisive steps to protect itself and suggest the reform of the UN to return its historic mission. President of Ukraine. Kiev, 27 Sep. Disponível em: http://www.president.gov.ua/ en/news/ukrayina-robitime-rishuchi-kroki-dlya-svogo-zahistu-ta-zapro-36030. Acesso em: 11/06/2016.

Robbinson, J. 2013. Why Syria? An Examination of the Iran-Iraq-Syria Pipeline. Folow the Money Daily. Fayetteville, 27 aug. Disponível em: https://ftmdaily.com/ what-jerry-thinks/whysyria/. Acesso em: 10 dez. 2015.

Rodgers, L., Gritten, D., Offer, J., Asare, P. 2015. Syria: The story of the conflict. $B B C$, London, 9 oct. Disponível em: http://www.bbc.com/news/world-middle-east-26116868. Acesso em: 12 nov. 2015.

Russia confirms S-400... 2015. Russia Confirms S-400 Air Defense System Put on Combat Duty in Syria. Sputnik Newe. Moscow, 26 Nov. Disponível em: http:// sputniknews.com/military/20151126/1030814269/s-400-combat-duty.html. Acesso em: 12 jun. 2016.

Russia. 2013. The Foreign Policy Concept of the Russian Federation. Moscow, 12 feb. Disponível em: http://www.rusemb.org.uk/in1/. Acesso em: 15 nov. 2015.

Russian Airbase... 2015. Russian airbase in Syria: RT checks out everyday life at Latakia airfield. Russia Today. Moscow, o3 Oct. Disponível em: https://www. rt.com/news/317528-latakia-russian-khmeimim-airbase/. Acesso em: 12 jun. 2016.

Snegovaya, M. 2015. Putin's Information Warfare in Ukraine: Soviet Origins of Russia's Hybrid Warfare. Washington: Institute for the Study of War.

Syria death toll: UN envoy estimates 400,000 killed. 2016. Aljazeera, Doha, 23 may. Disponível em: http://www.aljazeera.com/news/2016/04/staffan-de-mistura-400000 -killed-syria-civil-war-160423055735629.html. Acesso em: 11 jun. 2016. 
Un - United Nations. 2014. Security Council - Veto List. New York, Dag Hammarskjöld Library. Disponível em: http://research.un.org/en/docs/sc/ quick/veto. Acesso em: 13 out. 2015.

Unher - United Nations High Commissioner for Refugees. 2015. Press Release. Geneva, 09 set. Disponível em: http://unhcr.org/4million/\#_ $\mathrm{ga}=1.168360609 .121506812$ 2.1447886650. Acesso em: 07 nov. 2015.

Xenakis, J. J. 2015. World View: Russia’s Military Buildup a Game-Changer in Syria. Breitbart. 29 Nov. Disponível em: http://www.breitbart.com/national-security/2015/11/29/world-view-russias-military-buildup-a-game-changer-in-syria/. Acesso em: 11 jun. 2016. 


\section{NOTAS}

1. O acordo Sykes-Picot, assinado em 1916 inicialmente pela França e Inglaterra, e depois pela Rússia, dividia os territórios turco-otomanos em esferas de influência para as três potências acima citadas. Com a Revolução Bolchevique em 1917, a Rússia renunciou ao tratado.

2. Aghayev e Katman (2012) apontam que a posição da Síria era importante por sua localização geoestratégica; caso os norte-americanos instalassem suas ogivas em submarinos no Mediterrâneo, os russos poderiam também fazê-lo a partir do território sírio.

3. Insurreições ocorridas no Oriente Médio e no norte da África, que tiveram início em 2011 e atingiram países como Tunísia, Egito, Líbia, Síria e Iêmen.

4. Sendo que a população síria é de 22,1 milhões, mais de 11,7 milhões de pessoas já foram afetadas pelo conflito, de acordo com dados do Unher (2015).

5. Grupo extremista que se desenvolveu a partir das ações da al-Qaeda, no Iraque.

6. A utilização da normativa defensiva-reativa deve ser compreendida como uma valorização dos espaços multilaterais de negociação (em contraponto à securitização da agenda internacional) e ao viés normativo (no sentido de juridicista) da operacionalização destas diretrizes de política externa russa.

7. A referência aqui é aos territórios de Tchetchênia, Daguestão, Ingushétia (dentre outros), em cujos a ação de grupos extremistas é recorrente. 


\section{A GUERRA HÍBRIDA E O PAPEL DA RÚSSIA NO CONFLITO SÍRIO}

\section{RESUMO}

O presente artigo objetiva demonstrar a intervenção militar da Rússia na Síria enquanto guerra híbrida e enquanto evidência da atuação russa como polo internacional. Ademais, a intervenção na Síria parece plausível para frear o fluxo de refugiados à Europa e, indiretamente, para barganhar frente aos países europeus uma resolução do conflito ucraniano.

Palavras-chave: Guerra Híbrida; Rússia; Guerra na Síria; Refugiados.

\section{ABSTRACT}

This paper aims to characterize the Russian military intervention in Syria as a hybrid warfare and as an evidence of Russia acting as a pole in the international system. Furthermore, the intervention may reduce the migratory flow to Europe, giving Russia an object of bargain to solve the Ukrainian crises.

Keywords: Hybrid Warfare; Russia; Syrian War; Refugees.

Recebido em: 12/04/2016. Aceito para publicação em: 13/06/2016. 